\title{
Education and leadership
}

\section{Integration in stroke services: the challenges for primary and community care services}

\author{
Juan I Baeza BA MSc PhD \\ Lecturer in Health Policy \\ Alec Fraser BA MA \\ Research Associate \\ Dr Annette Boaz \\ Reader in Health Care Research \\ St. George's, University of London \& Kingston University, Grosvenor Wing, Cranmer Terrace, London \\ SW17 ORE, UK \\ On behalf of the European Implementation Score (EIS) Collaborative Group
}

\begin{abstract}
Objectives A number of evidence-based interventions are now available for stroke patients. Good quality stroke care involves a range of health professionals located across ambulance, hospital, community and primary care services. This study examined the perspectives of healthcare workers involved in stroke care in two different English case study sites on the integration challenges stroke care presents.

Methods Two qualitative case studies were carried out, including 45 semi-structured interviews with clinicians and managers associated with two different hospitals providing specialised stroke services. Findings High levels of organisational, functional,

fessionals delivering post-acute care. These findings are linked to the prevalence or lack of normative and systemic integration in each respective stage of care.

Conclusions Emphasis on the need to treat stroke as an emergency condition in England over recent years has created a context in which normative and systemic integration often occurs amongst clinicians that deliver emergency and acute stroke care, aiding the development of organisational, functional, service and clinical integration across the case study sites. In contrast, integration between hospital and community (rehabilitation and general practice) care is frequently less successful.
\end{abstract} service and clinical integration amongst clinicians that deliver emergency and acute stroke care were identified. This is frequently lacking amongst pro-
Keywords: integration, qualitative research, stroke care, stroke units

\section{Introduction}

Stroke is one of the leading causes of mortality and morbidity in the world. ${ }^{1}$ Although stroke was traditionally associated with few treatment options, the introduction of a number of evidence-based interventions have improved patient care and outcomes in recent years. ${ }^{2,3}$ The two most important interventions are the introduction of stroke units (SUs) that offer specialised inpatient co-ordinated care for stroke patients and thrombolysis, the administration of a 'clot-busting' drug, although only appropriate for less than a quarter of patients with an ischemic stroke. $^{3-5}$

According to various national guidance documents an ideal trajectory for a person who has had a stroke is to be taken by ambulance to the emergency department of a hospital with an SU; various treatments and assessments will be carried out in the emergency and radiology departments by stroke specialists and the patient will be transferred to the SU where further services will be provided by a multidisciplinary spe- 
cialist stroke team. ${ }^{6-9}$ Following a one to two week stay in the SU, depending on the patient's condition, the patient will be discharged and provided with a range of community rehabilitation and primary care services until patient goals are met; for up to a year postdischarge. From this simplified patient journey it is clear that there are a number of integration challenges for the various services, departments and clinicians involved in stroke care.

\section{Healthcare integration}

Integration of health services is thought to be important in achieving effective and efficient services for patients in general and for patients with long term conditions and those with multiple morbidities in particular. ${ }^{10,11}$ The aim of integration is to reduce fragmentation and to improve the continuity and coordination of care. ${ }^{12}$ There are a number of different forms of integration, this paper focuses on a type of vertical integration, entailing the extension of an organisation's activities upwards or/and downwards; for example, hospital care services integrating downwards with primary care or community care services. ${ }^{13}$ However, the term integration is rather elastic as it can refer to the complete formal merger of services (real integration) and much looser and informal linkages that can be developed within existing systems (virtual integration). ${ }^{14}$

Our data was analysed using Fulop et al's typology (see Table 1) of healthcare integration (adapted from work by Contandriopoulos and Shortell)..$^{10,15,16}$

Our focus is on organisational, functional, service and clinical integration and how far these have been achieved from the perspective of professionals delivering stroke care in England. Our data show the different challenges faced by teams working in different contexts and how these are impacted on by elements of normative and systemic integration.

\section{Methods}

The case studies focused on two SUs but included community and general practice (GP) services. Qualitative case studies allowed the researchers to explore stroke services in-depth and to ask the relevant 'how' and 'why' questions that emerged about how the different dimensions of integration affected stroke care at different stages of patients' pathways. ${ }^{17} \mathrm{~A}$ comparative case study design was used to facilitate the construction of a database comprising 45 interviews, with both internal and external validity. ${ }^{18,19}$

The two case study sites comprised of one rural site in an isolated part of eastern England and one urban site in a large city in the south east thereby capturing data from different contexts in terms of patient demography; influence and existence of competing hospitals; difficulties in attracting and retaining skilled staff; and differences in community care arrangements. The case studies examined the delivery of stroke services so the interview sample included a range of clinical and managerial staff from the SU, emergency medicine, radiology, the ambulance service, community rehabilitation services, commissioners of services and GPs, see Table 2 below.

The interviews were conducted by AF between October 2010 and September 2011. They were recorded, transcribed and then entered into Nvivo for coding.

Table 1 Integration typology (adapted from Fulop et al. 2005) ${ }^{10}$

\begin{tabular}{ll}
$\begin{array}{l}\text { Organisational } \\
\text { integration }\end{array}$ & $\begin{array}{l}\text { How the organisation is formally structured, by mergers and/or structural } \\
\text { change or virtually through contracts between separate organisations. }\end{array}$ \\
\hline $\begin{array}{l}\text { Functional integration } \\
\text { Service integration }\end{array}$ & $\begin{array}{l}\text { How non-clinical support and back-office functions are integrated. } \\
\text { How clinical services offered by the organisation are integrated with each } \\
\text { other. }\end{array}$ \\
Clinical integration & $\begin{array}{l}\text { How care for patients is integrated in a single process both intra and inter- } \\
\text { professionally through, for example, the use of shared guidelines along the } \\
\text { whole pathway of care. }\end{array}$ \\
In addition, two factors are crucial in determining how successful integration is: \\
Normative integration
\end{tabular}$\quad \begin{aligned} & \text { The role of shared values in co-ordinating work and securing collaboration in } \\
& \text { the delivery of healthcare. } \\
& \text { The coherence of rules and policies at the various levels of the organisation. }\end{aligned}$


Table 2 Roles of informants

\begin{tabular}{lcc}
\hline Professional group & England 1 & England 2 \\
\hline Commissioner & 3 & 0 \\
Manager & 4 & 3 \\
Doctor & 3 & 3 \\
Nurse & 7 & 4 \\
Healthcare Assistant & 1 & 1 \\
Therapist & 5 & 7 \\
GP & 1 & 1 \\
Ambulance service & 1 & 1 \\
Total & 25 & 20
\end{tabular}

Initial codes were generated from a close reading of the transcripts and were largely deductively based on the interview schedule. However, the data analysis had an inductive component and various vertical integration issues of stroke services were spontaneously raised by most informants in both case studies. AF led the analysis, but JB and $\mathrm{AB}$ also independently read a sample of transcripts and discussed the coding frame with AF to insure reliability.

\section{Results}

The empirical findings are presented with specific reference to the two broad dimensions of integration highlighted in the Fulop et al typology, ${ }^{12}$ that firstly comprise of the 'harder', organisational, functional, service and clinical integration and secondly, the 'softer' normative and systemic aspects of integration.

\section{Organisational, functional, service and clinical integration}

The ethos of treating stroke as an emergency condition has led to organisational and functional integration between ambulance and hospital services which treat patients with acute onset of stroke. The general level of responsiveness and expertise of ambulance crews has increased:

We're integrated into Health Pathways ... We've been integrated into it all along and have had our clinicians and our admin support and, sort of, service development staff involved in that right from the outset.

(Ambulance representative ECS2)
The specialised stroke team based on the SU have regular meetings with other members of staff involved in the stroke patient pathway promoting service integration:

We've tried to include [more than just SU staff] in things like the clinical governance group... one of the good things that's come out of the last few months is that we've built up very good relationships with some of the clinicians, particularly within radiology and A\&E.

(Stroke Nurse Specialist ECS1)

There are clearly defined and well integrated pathways of care for stroke patients in their pre-hospital and SU phases of care and there are important relational factors which aid clinical integration across and within professional boundaries:

... in the past dieticians have struggled because they've been met with quite a lot of resistance from like senior doctors. But here the doctors are very good, they are into their nutrition and they are very realistic in terms of their practice. (Dietician, ECS2)

These elements of integration are linked to effective communication, audit and leadership structures across the hospital sites. In contrast, the patient experience of post-hospital care is less integrated across clinical service lines. Indeed, this GP questions whether anyone really controls the stroke patient's clinical journey post-SU discharge:

... so once the hospital had done their bit [...] Whether that's all coordinated, it's just got to be done, you know, somehow, and I don't think there's anybody actually in control.

(GP, ECS2) 
This lack of follow-up is important because the responsibility for the care of a stroke patient post-SU discharge lies with their GP. SU based medical, nursing and therapies staff across both sites expressed concern about the lack of clinical integration post-SU discharge:

I don't have enough confidence in sending patients to the community and thinking that they're going to get what they need because... [many GPs] don't respond. And even then, again I don't know how much they're aware of the services within the community.

(In-Patient Occupational Therapist ECS2)

\section{Normative and systematic integration}

Our data suggested that healthcare professionals and managers involved in pre-hospital, emergency and SU care exhibit shared values which help coordinate work and secure collaboration in the delivery of stroke care. There is strong attachment to the evidence that 'time is brain ${ }^{20,21}$ Saver (2006, p. 263) suggests: the phrase 'time is brain' emphasizes that human nervous tissue is rapidly and irretrievably lost as stroke progresses and that therapeutic interventions should be emergently pursued. This general call to action (e.g. Gomez, 1993) in acute stroke care was adapted from its predecessor in acute coronary care ('time is muscle') both tracing their lineage to Benjamin Franklin's original aphorism, 'time is money') so suspected stroke patients should be taken quickly by ambulance to hospitals offering the panoply of services applied by specialists en route to the SU where a dedicated MDT will offer specialised care. It is this clinical integration - backed by aspects of normative and systemic integration which is seen as crucial and valued by professionals, managers and policy makers:

I just find it so exciting and so motivating. When I've done the thrombolysis round it is, it's high drama and high excitement...You know, so I have really tried to sell the magic of that. We really, at the top of the thrombolysis protocol we've got 'Time is Brain' in red letters.

(Clinical services manager ECS2)

These values and experiences are not shared along the pathway in primary and community care. Now that stroke care is a specialised emergency focused service, GPs have little experience of caring for these patients:

It's mainly identifying if they contact us rather than go straight to A\&E. They are now being encouraged to do that. And that has taken us out of the loop quite a bit.

(GP, ECS1)

Variability is a key finding in relation to post-hospital care for stroke patients. Both sites discharged patients to two different PCT community care providers. In
ECS1 one PCT employed specialist stroke therapists known to SU therapists with whom integrated care plans could be discussed, the other PCT did not employ specialist stroke rehabilitation staff, so hindering clinical integration:

We discharge to area A and area B... In area A, I'm really confident. I will put my referral in, and that patient will be seen [by a specialist OT] between a week or two weeks after my referral... In area B, there is actually no stroke OT to send them to or to refer them to... So I send in a referral and I don't know what happens... the service is certainly not joined up.

(Senior Hospital OT ECS1)

Our urban hospital (ECS2) also discharged patients to two different PCT areas, one of which employed a community stroke coordinator facilitating systemic integration; the second PCT lacked a coordinator, hindering integration:

[The area A community stroke coordinator] comes to our MDT meetings, she picks up all the area A patients, she then goes and visits them immediately after discharge, makes an appointment to see them again in six weeks and then sees them again in six months and then it's a year... There was supposed to be community stroke coordinator in area B, but she left...

(Consultant, ECS2)

\section{Discussion and conclusions}

These empirical data suggest that the conscious decision by senior stroke clinicians and policy makers to treat stroke as an emergency condition has created a context in which normative and systematic integration often flourishes between the various clinicians that provide emergency and hospital stroke care, allowing elements of organisational, functional, service and clinical integration (to a lesser or greater extent) to be achieved across emergency and hospital stroke care in both case study sites. In contrast, these normative and systemic elements are often lacking in the postspecialist hospital phase of treatment so that integration between hospital and community (rehabilitation and general practice) care is frequently less successful.

The management challenge lies with commissioners and designers of post SU care pathways to encourage normative integration beyond emergency and acute care in stroke, promoting cross-site working by therapists from SU and community teams and closer working between stroke specialists and GPs. Systemic integration in post $\mathrm{SU}$ care could be encouraged, perhaps by further work with stroke coordinators and by linking community based policy goals with funding 
implications. An alternative approach might be to extend the role of the SU outwards by organizationally integrating community services with the hospital (there are elements of this at ECS2) but this lacks effective functional, service and clinical elements as responsibility still rests with GPs not hospital consultants.

This study has indicated other issues that require further research including the perceived lack of integration within community care stroke services and the challenge of integrating services for stroke patients with co-morbidities.

\section{ACKNOWLEDGEMENTS}

We would like to thank Prof. Naomi Fulop, Prof. Charles Wolf and Dr Chris McKevitt who made useful comments to earlier drafts of a related paper. We would like to thank all those health care staff in England who participated in this study.

This work forms part of the European Implementation Score (EIS) project, funded by the EU 7th Framework Programme, which is a collaboration between King's College London, University of Florence, University of Lund, London School of Economics, University College London, the German Stroke Foundation and Charité - Universitätsmedizin Berlin. The work packages are lead by: Prof C Wolfe, Prof D Inzitari, Dr J Baeza, Prof B Norrving, Prof P Heuschmann, Prof A MacGuire, Prof H Hemmingway, Dr M Wagner and Dr C McKevitt This paper has been written by the authors on behalf of the Work Package 3 board.

\section{REFERENCES}

1 Strong K, Mathers C and Bonita R. Preventing stroke: saving lives around the world. Lancet Neurol 2007; 6:182-7.

2 NINDS. Tissue plasminogen activator for the treatment of acute ischaemic stroke. NEJM 1995;333:1581-7.

3 Stroke Unit Trialists' Collaboration. Organised inpatient (stroke unit) care for stroke. Cochrane Database Syst Rev. 2007;17;(4).

4 Langhorne P and Pollock A. With the Stroke Unit Trialists Collaboration. What are the components of effective stroke unit care? Age and Ageing 2002;31:36571.

5 Wardlaw JM, del Zoppo G, Yamaguchi T, Berge E et al. Thrombolysis for acute ischaemic stroke. (Cochrane Review).Cochrane Library, Issue 1, 2004.

6 NICE. Stroke: Diagnosis and initial management of acute stroke and transient ischaemic attack (TIA). NICE clinical guideline 68, 2008.
7 Department of Health. National Stroke Strategy. London: Department of Health, 2007.

8 Kjellström T, Norrving B and Shatchkute A. Helsingborg Declaration 2006 on European Stroke Strategies Cerebrovascular Diseases. Cerebrovascular Diseases 2007;23: 229-41.

9 Care Quality Commission.Supporting Life After Stroke. London: Care Quality Commission, 2011.

10 Fulop N, Mowlem A and Edwards N. Building Integrated Care. London: The NHS Confederation, 2005.

11 Goodwin N, Smith J, Davies A et al. Integrated Care for Patients and Populations: improving outcomes by working together. A report to the Department of Health and the NHS future forum. London: King's Fund, 2012.

12 Ouwens M, Wollersheim H, Hermens R, Hulscher M and Grol R. Integrated care programmes for chronically ill patients: a review of systematic reviews. International Journal of Quality in Health Care 2005;17:141-6.

13 Brown M and McCool BP. Vertical integration: exploration of a popular strategic concept. Health Care Management Review 1986;11:7-19.

14 Curry N and Ham C. Clinical and service integration: The route to improved outcomes. London: King's Fund, 2010.

15 Contandriopoulos AP, Denis JL, Touati N and Rodriguez. Intégration des soins: dimensions et mise en oeuvre. Ruptures, Revue Transdiciplinaire en Sante 2001;8(2):38-52.

16 Shortell SM. Remaking Health Care in America: The evolution of organised delivery systems. San Francisco, Jossey-Bass, 2000.

17 Yin R. Case Study Research. Design and Methods. California: Sage, 2003.

18 Eisenhardt K. Building theories from case study research. Academy of Management Review 1989;14(4): 532-50.

19 Langley A. Strategies for theorising from process data. Academy of Management Review 1999;24(4):691-710.

20 Saver JL. Time is brain - quantified. Stroke 2006;37:2636.

21 Gomez C. Time is brain. Journal of Stroke \& Cerebrovascular Diseases 1993;3:1-2.

\section{ADDRESS FOR CORRESPONDENCE}

\section{Juan I Baeza}

King's College London

Department of Management

150 Stamford Street

London SE1 9NH

UK

Email: Juan.baeza@kcl.ac.uk

Accepted December 2012 